\section{Assessing the Global Usability of Dry Powder Inhalers: Anal- ysis of Six Devices Widely Used for Asthma}

\author{
Dal Negro RW'1, Turco $\mathrm{P}^{2}$ and Povero $\mathrm{M}^{3 *}$ \\ ${ }^{1}$ National Centre for Respiratory Pharmacoeconomics and Pharmacoepi- \\ demiology, Verona, Italy
}

${ }^{2}$ Research \& Clinical Governance, Verona, Italy

${ }^{3}$ AdRes Health Economics and Outcome Research, Torino, Italy

\begin{abstract}
Background: Several patient-related and unrelated factors can contribute to usability of Dry Powder Inhalers (DPIs), and the Global Usability Score (GUS) proved to be a comprehensive tool of objective investigation.
\end{abstract}

Aim: The study was to assess and compare the usability of six most used DPIs in bronchial asthma by GUS.

Methods: The GUS questionnaire was administered to persistent asthma patients needing long-term inhalation treatment. Six DPIs were compared: Breezhaler, Diskus, Ellipta, Nexthaler, Spiromax and Turbohaler. Patients' previous experience with DPIs was also checked and used to classify patients as experienced or naïve, respectively. A Bayesian Indirect Comparison (IC) model was built to assess the "global usability" ranking.

Results: A total of 148 subjects were enrolled: 74 tested Breezhaler, Spiromax, Nexthaler and Ellipta simultaneously, while 74 tested Breezhaler, Spiromax, Diskus and Turbohaler. Ellipta was the most usable device in experienced patients ( $80 \%$ probability), followed by Diskus and Turbohaler which ranked second or third $(\geq 70 \%$ probability), and by Spiromax and Nexthaler ( $\geq 90 \%$ probability). Usability of naïve patients differed significantly: Turbohaler ranked first $(70 \%$ probability), while Diskus, Spiromax and Nexthaler ranked second, followed by Ellipta. Both groups agreed to rank Breezhaler as the least usable device ( $\geq 99 \%$ probability).

${ }^{*}$ Corresponding author: Povero M, AdRes Health Economics and Outcome Research, Torino, Italy, Tel: +39 0117651239; E-mail: m.povero@adreshe.com

Citation: Dal Negro RW, Turco P, Povero M (2021) Assessing the Global Usability of Dry Powder Inhalers: Analysis of Six Devices Widely Used for Asthma. J Pulm Med Respir Res 7: 064.

Received: April 08, 2021; Accepted: April 30, 2021; Published: May 07, 2021

Copyright: (c) 2021 Dal Negro RW, et al. This is an open-access article distributed under the terms of the Creative Commons Attribution License, which permits unrestricted use, distribution, and reproduction in any medium, provided the original author and source are credited.
Conclusion: DPIs are characterized by different degrees of usability in asthma. The ranking of DPIs' usability changes significantly according to their suitability. This evidence should be carefully considered when prescribing or switching a DPI in asthma patients.

Keywords: Airway obstruction; Bronchial asthma; Dry powder inhalers; Global usability score; Usability

\section{Introduction}

The effectiveness of respiratory therapy through inhalation devices, and in particular through Dry Powder Inhalers (DPIs), still is a critical issue [1-5].

Several aspects related to DPIs use had been investigated, particularly those depending of patients' beliefs [6], then being both the acceptability and the preference of different DPIs have been mainly checked and regarded as the most reliable indicators by the majority of Authors [7-13].

Nevertheless, also some patient-unrelated factors are equally involved in determining the DPIs' usability, that is a more complex, multifaceted and comprehensive parameter to use for comparing and discriminating the convenience of DPIs [14-17].

There is consolidated evidence that patients are unable to use all DPIs equally well [18-21]. Their technological peculiarities require different patterns of inhalation flows thus likely representing a major factor that is able to variably affect the usability of DPIs presently available, and consequently their inhalation performances [21]. This assumption is of great clinical value, in particular in patients suffering from persistent asthma who need a long-term inhalation therapy.

Patients' perceptions and empowerment were highly valued from this point of view, even if only a few studies investigated and assessed the correspondence between the patients' beliefs and the effective usability of DPIs in real-life by means of specific and comprehensive instruments [13,22-24].

The Global Usability Score (GUS) Questionnaire was recently introduced for assessing, compare and ranking objectively the usability of different DPIs [17] as it allows the assessment of a much wider range of determinants of DPIs' usability, included the related cost [25].

\section{Aim}

The aim of the study was to assess and compare the usability of six most used Dry Powder Inhalers (DPIs) in a cohort of patients with persistent asthma.

\section{Methods}

The GUS questionnaire was administered to consecutive subjects suffering from persistent asthma and needing long-term inhalation therapy who referred to the CEMS Specialist Centre (Verona-Italy) 
over the trimester October-December 2018. The GUS questionnaire is an anonymous operational tool specifically developed for assessing and comparing objectively the usability of four different simultaneously (see the Appendix). This questionnaire was chosen as it allows to investigate a wider range of factors affecting usability, and takes also into account the nurse's assessment of patients' procedures for inhalation [25] (see the Appendix). In order to avoid any influence on the subject's responses, the pre-printed score of values pertaining to each item of the questionnaire was obviously not visible in the form distributed to subjects, and it was only available in the mother-version of the Questionnaire. The final GUS score was calculated by the steering committee only once the questionnaire had been definitively filled by patients.

Six DPIs were compared: Breezhaler, Diskus, Ellipta, Nexthaler, Spiromax, Turbohaler and Genuair. These inhalers were chosen because requiring variable number of actions for their actuation (7 for Breezhaler, 4 for Ellipta and Turbohaler and 3 for the remaining devices) and because differently characterized in terms of their intrinsic resistance (ranging $0.017-0.039 \mathrm{kPa}^{0.5} \mathrm{~L} / \mathrm{min}$ ).

Two expert nurses, highly trained in educational programs and specifically familiar with the technical and the psychological aspects of the GUS Questionnaire for two years were dedicated to patients' interviews. They also supervised, checked, assessed and validated all patients' procedures for inhalation. The study consisted in four different steps:

Step 1: The nurse checked the basic knowledge of each patient in the DPIs' use.

Step 2: The nurse carefully displayed the proper functioning of each DPI in random order. All explanations were provided according to a standardized sequence of sentences. The duration of each explanation had been previously standardized for each DPI. Patients were then requested to declare their preference "at glance" and to specify the reason for their preference. All information collected during this phase was reported in the \# 1 box of the Assessing Track (AT) section of the questionnaire (see the Appendix).

Step 3: Each patient was then requested to prepare the actuation of each device autonomously, while the nurse monitoring and assessing her/his technicality. The nurse also valued the critical points occurred; counted the number of attempts needed for actuating the device properly, and measured the time spent. Data on patients' beliefs, the reasons of their choice, and quantitative data of the nurse's direct measurements were reported in boxes \# 2-4 of the GUS questionnaire (see the Appendix).

Step 4: Finally, data from other ten closed questions pertaining to subjects' perception of each device were also collected and reported in box \# 5 (see the Appendix).

At the end of each box of the Assessing Track, sub-score is available and easily calculated. At the end of the questionnaire, the final Global Usability Score is obtained by summing-up all the subscores for each DPI. The GUS final score ranges 0-50 points; higher the value of the score for each DPI, higher the corresponding usability will be.

The study was approved by the Ethical and Scientific Commission of the National Centre for Respiratory Pharmacoeconomics and Pharmacoepidemiology during the session of January $4^{\text {th }}, 2018$. Only data collected from patients who gave their informed consent to the investigation and to the possible use of information for scientific purposes were used for the present study.

\section{Statistics}

Patients' characteristics were summarized as mean and Standard Deviation (SD) for continuous data or percentage for dichotomous and categorical variables. Baseline characteristics between subgroup of patients who tested the different sequences of devices were compared using the non- parametric Wilcoxon test for continuous variables and the exact Fisher test for dichotomous/categorical data. In order to control the selection bias due to the group of patients previously instructed to DPI (experienced patients) and those not instructed (naïve patients), they were analyzed separately.

All pair wise comparisons between the six DPIs were merged using a Bayesian Indirect Comparison (IC) model; technical details of the model were previously described [26]. Briefly, IC models are used for pooling quantitative results from multiple studies and for assessing the effect between two or more treatments [27]. In our context, "multiple studies" meant groups 1 and 2, and "treatments" means devices. This approach is particularly advantageous because all devices under comparison are incorporated into a single model even if they are not compared in the same questionnaire. Moreover, the Bayesian technique enables rank ordering of each device (i.e. the probability associated to each one being the $1^{\text {st }}, 2^{\text {nd }}, 3^{\text {rd }} \ldots$ best device) hence it results in a "global usability" ranking. As no restrictive inclusion criteria were assessed on the enrolled population, high variability in patients' characteristics was expected. To take into account such heterogeneity, the pair wise comparisons were combined in the Bayesian IC framework according to a Random-Effect (RE) model: Each individual i provides an estimate of the device effect $\delta_{i}$, which is not equal, but similar, to the real effect $\mathrm{d}$; that is each effect $\delta_{i}$ comes from a normal distribution with mean $d$ and variance $\tau^{2}$ representing the variability between respondents. Estimated GUS score for each device was presented as mean and 95\% Credibility Interval (CrI).

According to previous analysis on COPD patients [26], the GUS of the first preferred device was at least 5 points higher than the second preferred device $(S D=20)$. By using the formula for matchedpairs sample (as each patient tests 4 devices), with 5\% type I error and $80 \%$ statistical power, at least 126 patients should be enrolled in the study.

Statistical analyses were performed with $\mathrm{R}$ statistical software version 3.6.3 [28], a p-value lower than 0.05 was considered to indicate evidence of differences in the evaluated variables. The Bayesian IC model was developed by using the software package Win BUGS 1.4.3. [29].

\section{Results}

A total of 148 subjects accepted to partecipate in the study: 74 tested Breezhaler, Spiromax, Nexthaler and Ellipta simultaneously (Group 1), while other 74 tested Breezhaler, Spiromax, Diskus and Turbohaler (Group 2). Subjects entered the two groups according to a pre-defined random order.

About $76 \%$ of subjects were already familiar with DPIs. In particular, $44 \%$ had also already been instructed in the use of Metered 
Citation: Dal Negro RW, Turco P, Povero M (2021) Assessing the Global Usability of Dry Powder Inhalers: Analysis of Six Devices Widely Used for Asthma. J Pulm Med Respir Res 7: 064.

Dose Inhalers (MDIs), and 10\% of Soft Mist Inhalers (SMIs). Only $17 \%$ of naïve patients were familiar in the use of MIDs, but no one in SMIs use (Table 1).

Group 1 and Group 2 were not different by age, sex, cultural level and previous experience with other inhalation devices (Table 1). Only the regional distribution of Group 1 and 2 (for both experienced and naïve patients) was different $(\mathrm{p}<0.05)$.

Evidence network obtained from the 148 questionnaires is reported in figure 1. Ellipta, Nexthaler and Breezhaler were directly compared only in Group 1; Turbohaler and Diskus were directly compared only in Group 2; Breezhaler and Spiromax were directly compared in both Groups 1 and 2.

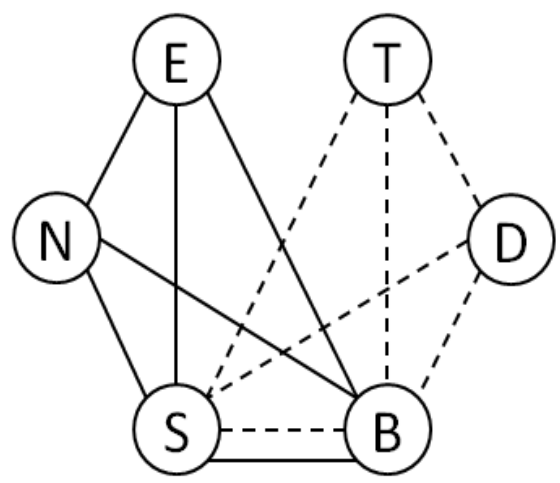

Figure 1: Evidence network based on patients in the two groups; solid lines represent comparison in group 1 and dotted lines represent comparisons in group 2.

E: Ellipta, N: Nexthaler, S: Spiromax, B: Breezhaler, D: Diskus, T: Turbohaler.

The estimated GUS values for each device considered in the study are reported in table 2 . The usability of Breezhaler seems not associated with the patient's original level of previous instruction as it was characterized by the lowest GUS score both in the experienced and in the naïve group. Furthermore, in the DPI experienced group, the trend in usability proved quite linear from Ellipta (with the highest GUS) to Breezhaler (the lowest GUS), whereas, in the naïve group, GUS scores of almost all devices (with the exclusion of Turbohaler ranked first) resulted very similar and also 95\% CrI were very close.

The histograms of rankings generated by the Bayesian pooling in originally instructed and in naïve asthmatic patients are reported in figure 2. The histograms reflect 100,000 iterations and consist of as many histograms as the devices included in the analysis. In each panel, each histogram shows the percent distribution of the simulations across ranks $1^{\text {st }}$ (the greatest GUS) to $6^{\text {th }}$ (the lowest GUS), while the $y$-axis shows the probability on a 0 to 1 scale. As previously reported in table 2 for the DPI experienced asthma patients, the individual ranking of the 6 devices was straightforward: Ellipta $1^{\text {st }}$ (up to $3^{\text {rd }}$ ), Diskus tied Turbohaler $\left(2^{\text {nd }}\right.$ to $\left.3^{\text {rd }}\right)$, Spiromax $\left(4^{\text {th }}\right)$, Nexthaler $\left(5^{\text {th }}\right)$, and Breezhaler $6^{\text {th }}$ (Figure 2). In particular, Ellipta had almost $80 \%$ probability to be the first preferred device; Diskus and Turbohaler had about $70 \%$ of probability to be $2^{\text {nd }}$ or $3^{\text {rd }}$. For the naïve population the ranking order resulted very different with respect to experienced patients: Turbohaler $1^{\text {st }}$, Diskus, Spiromax and Nexthaler tied ( $2^{\text {nd }}$ to $\left.4^{\text {th }}\right)$, Ellipta $5^{\text {th }}$ and Breezhaler $6^{\text {th }}$ (Figure 2).

\section{Discussion}

The prescription of the most suitable DPI to use (or to switch) is a critical issue since long ago [1-2]. Patients' opinion has been increasingly valorized in terms of DPI preference over the last decade, being the majority of data presently available derived from studies mainly focusing on the role of those criteria that are strictly related to patients' beliefs. As a consequence, intuitivity, satisfaction, willingness to use, preference "at glance", dexterity, ease-of-use, and acceptance were the criteria most widely adopted for comparing different DPIs [7-13].

\begin{tabular}{|c|c|c|c|c|c|c|c|c|}
\hline & \multicolumn{4}{|c|}{ Instructed to DPI (experienced patients) } & \multicolumn{4}{|c|}{ Not instructed to DPI (naïve patients) } \\
\hline & Total & Group 1 & Group 2 & $\mathbf{p}$ & Total & Group 1 & Group 2 & $\mathbf{p}$ \\
\hline $\mathrm{N}$ & 112 & 54 & 58 & & 36 & 20 & 16 & \\
\hline Instructed to MDIs & $43.7 \%$ & $48.1 \%$ & $39.7 \%$ & 0.4426 & $16.7 \%$ & $20.0 \%$ & $12.5 \%$ & 0.6722 \\
\hline Instructed to SMIs & $10.4 \%$ & $14.0 \%$ & $7.0 \%$ & 0.3406 & $0.0 \%$ & $0.0 \%$ & $0.0 \%$ & NA \\
\hline Age $($ mean \pm SD) & $45.3 \pm 15.5$ & $44.1 \pm 13.8$ & $46.3 \pm 16.9$ & 0.4839 & $43.4 \pm 16.6$ & $43.5 \pm 16.6$ & $43.2 \pm 17.2$ & 0.7501 \\
\hline Sex (male) & $45.9 \%$ & $45.1 \%$ & $46.6 \%$ & $>0.999$ & $55.6 \%$ & $50.0 \%$ & $62.5 \%$ & 0.68 \\
\hline Country & & & & 0.0236 & & & & 0.0003 \\
\hline North & $66.1 \%$ & $77.8 \%$ & $55.2 \%$ & & $63.9 \%$ & $90.0 \%$ & $31.3 \%$ & \\
\hline Center & $16.1 \%$ & $7.4 \%$ & $24.1 \%$ & & $13.9 \%$ & $0.0 \%$ & $31.3 \%$ & \\
\hline South and Islands & $17.9 \%$ & $14.8 \%$ & $20.7 \%$ & & $22.2 \%$ & $10.0 \%$ & $37.5 \%$ & \\
\hline Education & & & & 0.8516 & & & & 0.1445 \\
\hline Primary & $1.9 \%$ & $2.1 \%$ & $1.8 \%$ & & $6.2 \%$ & $11.1 \%$ & $0.0 \%$ & \\
\hline Lower secondary & $29.6 \%$ & $25.5 \%$ & $33.3 \%$ & & $25.9 \%$ & $16.7 \%$ & $37.5 \%$ & \\
\hline Upper secondary & $57.9 \%$ & $61.7 \%$ & $54.4 \%$ & & $49.7 \%$ & $44.4 \%$ & $56.3 \%$ & \\
\hline Degree & $10.6 \%$ & $10.6 \%$ & $10.5 \%$ & & $18.2 \%$ & $27.8 \%$ & $6.3 \%$ & \\
\hline
\end{tabular}

Table 1: Baseline characteristics of patients evaluated devices using the Global Usability Score questionnaire.

Group1 tested Breezhaler, Spiromax, Nexthaler and Ellipta; Group 2 tested Breezhaler, Spiromax, Diskus and Turbohaler; DPIs: Dry Powder Inhalers, MDIs: Metered Dose Inhalers, SMIs: Soft Mist Inhalers, SD: Standard Deviation.

Comparison between experienced and naïve patients: instructed to MDI ( $\mathrm{p}=0.0014)$, instructed to $\mathrm{SMI}(\mathrm{p}=0.0655)$, age $(\mathrm{p}=0.2956)$, sex $(\mathrm{p}=0.3236)$, country $(\mathrm{p}=0.8469)$, and education $(\mathrm{p}=0.3527)$. 


\begin{tabular}{|c|c|c|c|}
\hline Device & Mean GUS (95\% CrI) & Device & Mean GUS (95\% CrI) \\
\hline Ellipta & $28.99(21.72$ to 35.87$)$ & Turbohaler & $26.66(17.15$ to 36.4$)$ \\
\hline Diskus & $24.87(17.98$ to 32.16$)$ & Diskus & $21.87(12.54$ to 31.34$)$ \\
\hline Turbohaler & $23.29(16.54$ to 30.45$)$ & Spiromax & $19.74(12.47$ to 26.95$)$ \\
\hline Spiromax & $16.71(11.66$ to 21.85$)$ & Nexthaler & $19.05(10.31$ to 27.66$)$ \\
\hline Nexthaler & $12.62(5.98$ to 18.88$)$ & Ellipta & $17.51(8.9$ to 25.88$)$ \\
\hline Breezhaler & 5.01 (4.11 to 5.9$)$ & Breezhaler & $5.69(3.47$ to 7.91$)$ \\
\hline
\end{tabular}

Table 2: Mean and 95\% credibility interval of GUS resulting for each device from Bayesian analysis for asthma patients instructed and nor instructed to DPIs (device in each group are ranked from the first to the last according to the mean GUS).

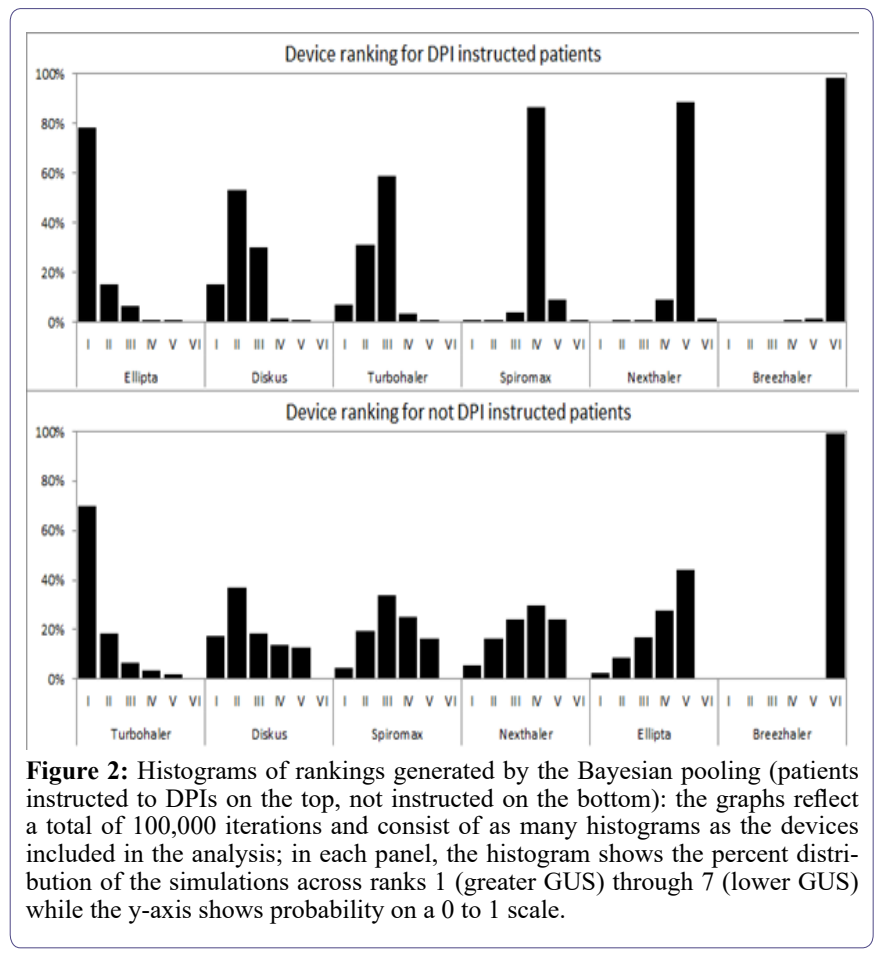

On the contrary, the assessment of those aspects that are totally or partially independent of patients' subjectivity (namely, the effect of the peculiar engineering of the device, the inspiratory flow required for actuation, the training track needed for their appropriate use, and the related cost) did not receive the same attention from this point of view. However, also these factors can in fact further contribute to the overall picture of the so called "usability" of inhalation devices and of DPIs in particular, much more that the patients' age, gender and educational level as confirmed by data of the present study. Actually, it is well known that different regimens of DPIs' intrinsic resistance can lead to different performances in terms of lung deposition of respiratory drugs and of clinical outcomes due to the variable inspiratory flow required for their adequate inhalation, even if patients are unaware of their relative role [17-18,24].

So much so, in primary and secondary care, more than $30 \%$ of UK physicians valued the device before deciding the respiratory drug to prescribe. Moreover, a great proportion of UK health professionals $(87 \%)$ stated to be concerned about possible problems arising if the inhalation device is not specified and $86 \%$ of them also state that
DPIs are non-interchangeable and that their unmotivated substitution would have a negative impact [30,31].

Usability is a complex and multifaceted parameter that contributes to the objective and comprehensive assessment of DPI convenience in real life because it takes into account a large panel of determining factors. The comprehensive value of usability as the discriminating parameter for the proper choice of the DPI mainly consists in its multidimensional assessment of a weighted mix of subjective (namely, intuitivity, satisfaction, willingness to use, preference "at glance”, dexterity, ease-of-use, acceptance, etc.) and objective (such as, those variably independent of patients' convincement and beliefs, cost included) domains, all contributing to and affecting the overall convenience of each DPI in real life. Precisely for these reasons the multidimensional GUS Questionnaire was preferred in the present study to other instruments [11,14,23,32] for comparing and ranking six different DPIs in asthma patients objectively [17].

Even if no one of the six DPIs tested achieved the ideal GUS top score of 50 points, their usability proved significantly different and a clear ranking was possible. Actually, when compared by their GUS score, DPIs proved variably usable in asthma patients: Some DPIs should be preferred in previously instructed rather than in naïve asthma patients and vice versa. In other words, asthma patients already familiar with DPIs (namely, the majority of patients in present times) behave in a different way when compared to naïve patients. In order to optimize the effectiveness and convenience of their therapeutic strategy these patients should need DPIs differently characterized from those of naïve patients, regardless the number of maneuvers needed for their actuation. This particular evidence, quite novel to our best knowledge, should be highly considered in clinical practice before any DPI prescribing. This evidence further emphasizes the concept that all asthma patients are unable to use all DPIs equally well and effectively [18].

Nevertheless, randomized clinical trials and patient-centered studies in unselected samples of subjects should be continuously encouraged in order to provide more suitable data in real-life conditions [30].

The present investigation has some limitations. The study is a monocentric study, even if patients enrolled were from several Italian regions. The original whole sample of patients had to be divided in two sub-groups because the GUS Questionnaire only consents the comparison of four devices simultaneously. On the other hand, the simultaneous comparison of more than four DPIs would create severe problems in terms of patients' reliability of their responses. Finally, despite the strict control of both the quality and duration of the nurses' explanation of each DPI functioning, it was any way possible that minimal differences would occur in transferring the messages, even if the high predictivity of GUS tends to exclude the occurrence of substantial biases from this point of view. Points of strengths are the strict randomized procedure for checking and compare the DPIs use together with the statistical model adopted, such as the Bayesian Indirect Comparison that reflects a total of 100,000 iterations.

\section{Conclusion}

The usability of DPIs is a complex issue indeed, and it is not merely a synonymous of ease-of-use or of intuitivity. One single parameter for the DPI choice is unable to represent per sé the overall 
Citation: Dal Negro RW, Turco P, Povero M (2021) Assessing the Global Usability of Dry Powder Inhalers: Analysis of Six Devices Widely Used for Asthma. J Pulm Med Respir Res 7: 064.

usability of DPIs exhaustively, in particular if only based on patients subjectivity and beliefs. DPIs are variably characterized by different degrees of usability in asthma. In the aim to approximate the true usability of different DPIs in asthma patients at the best possible level, only a multidimensional and a multi-domain assessment is recommended. Stemming from this assumption, it would become ever much clear that the current convincement that "one size fits for all" is absolutely misleading in clinical practice when dealing with DPIs, particularly in asthma. The ranking of DPIs' usability changes significantly according to their suitability. This evidence should be carefully considered when prescribing or switching a DPI in asthma patients.

\section{Contributes}

Roberto Dal Negro planned the study, collected data and wrote the manuscript. Paola Turco collected data, provided critical feedback and contributed to the final version of the manuscript. Massimiliano Povero performed the statistical analysis and wrote the manuscript.

\section{Conflict of Interest}

The authors declare no conflict of interest.

\section{References}

1. Crompton GK (1982) Problems patients have using pressurized aerosol inhalers. Eur J Resp Dis 119: 101-104.

2. Brokllebank D, Ram F, Wright J, Barry P, Cates C, et al. (2001) Comparison of the effectiveness of inhaler devices in asthma and chronic obstructive airways disease: A systematic review of the literature. Health Technol Assess 5: 1-149.

3. Barry PW, O'Callagnan C (2003) The influence of inhaler selection on efficacy of asthma therapies. Adv Drug Deliv Res 55: 879-923.

4. Virchow JC, Crompton GK, Negro RWD, Pedersen S, Magnan A, et al (2008) Importance of inhaler devices in the management of airway diseases. Respir Med 102: 10-19.

5. Thomas M, Williams AE (2005) Are outcomes the same with all dry powder inhalers? Int J Clin Pract Suppl 149: 33-35.

6. Barrons R, Pegram A, Borrens A (2011) Inhaler device selection: special considerations in elderly patients with chronic obstructive pulmonary disease. Am J Health Syst Pharm 68: 1221-1232.

7. Cross S (2001) Asthma inhalation delivery systems: The patient's viewpoint. J Aersol Med 1: 3-7.

8. Lenney J, Innes JA, Crompton GK (2000) Inappropriate inhaler use: Assessment of use and patient preference of seven inhalation devices. EDICI. Respir Med 94: 496-500.

9. Franks M, Briggs P (2004) Use of a cognitive ergonomics approach to compare usability of a multidose dry powder inhaler and a capsule dry powder inhaler: An open-label, randomized, controlled study. Clin Ther 26: 1791-1799.

10. Anderson P (2005) Patient preference for and satisfaction with inhaler devices. Eur Respir Rev 96: 109-116.

11. Tordera MP, Viejo JL, Sanchis J, Badia X, Cobos N, et al. (2008) Assessment of patient satisfaction and preferences with inhalers in asthma with the FSI-10 Questionnaire. Arch Broncopneumol 44: 346-352.

12. Schulte M, Osseiran K, Betz R, Wencker M, Brand P, et al. (2008) Handling of and preferences for available dry powder inhaler systems by patients with asthma and COPD. J Aerosol Med Pulm Drug Deliv 21: 321328.
13. Hantulik P, Wittig K, Henschel Y, Ochse J, Vahteristo M, et al. (2015) Usage and usability of one dry powder inhaler compared to other inhalers at therapy start: An open, non-interventional observational study in Poland and Germany. Pneumol Alergol Pol 83: 365-377.

14. Rajan SK, Gogtay JA (2014) Ease-of-use, preference, confidence, and satisfaction with Revolizer(®), a novel dry powder inhaler, in an Indian population. Lung India 31: 366-374.

15. Newman SP, Busse WW (2002) Evolution of dry powder inhaler design, formulation, and performance. Respir Med 96: 293-304.

16. Virchow JC (2005) What plays a role in the choice of inhaler device for asthma therapy? Curr Med Res Opin 4: 19-25.

17. Wieshammer S, Dreyhaupt J (2008) Dry powder inhalers: Which factors determine the frequency of handling errors? Respiration 75: 18-25.

18. Roberto WDN, Paola T, Povero M (2017) The global usability score: A novel comprehensive tool for assessing, ranking, and compare usability of inhalers in patients requiring airway treatments. J Pulm Respir Med 7: 2.

19. Gustafsson P, Taylor A, Zanen P, Chrystyn H (2005) Can patients use all dry powder inhalers equally well? Int J Clin Pract Suppl 149: 13-18.

20. Chrystyn K (2005) Do patients show the same level of adherence with all dry powder inhalers? Int J Clin Pract Suppl 149: 19-25.

21. Franks M, Briggs P (2004) Use of a cognitive ergonomics approach to compare usability of a multidose dry powder inhaler and a capsule dry powder inhaler: An open-label, randomized, controlled study. Clin Ther 26: $1791-1798$

22. Negro RWD, Povero M (2016) Dry-powder inhalers in patients with persistent airflow limitation: Usability and preference. Multiscip Respir Med 11: 31 .

23. Kozma CM, Slaton TL, Monz BU, Hodder R, Reese PR (2005) Development and validation of a patient satisfaction and preference questionnaire for inhalation devices. Treat Respir Med 4: 41-52.

24. Hantulik P, Wittig K, Henschel Y, Ochse J, Vahteristo M, et al. (2015) Usage and usability of one dry powder inhaler compared to other inhalers at therapy start: An open, non-interventional observational study in Poland and Germany. Pneumol Alergol Pol 83: 365-377.

25. Negro RWD, Turco P, Povero M (2021) The contribution of patients' lung function to the inspiratory airflow rate achievable through a DPIs' simulator reproducing different intrinsic resistance rates. Multidiscip Respir Med 16: 752 .

26. Negro RWD, Turco P, Povero M (2019) Patients' usability of seven most used dry-powder inhalers in COPD. Multidisciplinary Respiratory Medicine 14: 30 .

27. NICE Clinical Guidelines (2010) Venous thromboembolism: Reducing the risk of venous thromboembolism (Deep vein thrombosis and pulmonary embolism) in patients admitted to hospital. National Clinical Guideline Centre Acute and Chronic Conditions, London, UK.

28. R Core Team (2014) R: A language and environment for statistical computing. R Foundation for Statistical Computing, Vienna, Austria.

29. Lunn DJ, Thomas A, Best N, Spiegelhalter D (2000) WinBUGS - a Bayesian modelling framework: Concepts, structure, and extensibility. Statistics and Computing 10: 325337.

30. Price D, Thomas M, Mitchell G, Niziol C (2003) Improvement of asthma control with a breath-actuated pressurised metred dose inhaler (BAI): a prescribing claims study of 5556 patients using a traditional pressurised Metred Dose Inhaler (MDI) or a breath-actuated device. Respire Med 97 : 12-19.

31. Price D (2005) Do healthcare professionals think that dry powder inhalers can be used interchangeably? Int J Clin Pract Suppl 149: 26-29. 
Citation: Dal Negro RW, Turco P, Povero M (2021) Assessing the Global Usability of Dry Powder Inhalers: Analysis of Six Devices Widely Used for Asthma. J Pulm Med Respir Res 7: 064.

32. Zervas E, Samitas K, Gaga M (2016) Assessment of satisfaction with different dry powder inhalation devices in Greek patients with COPD and asthma: The ANASA study. Intern J COPD 11: 1845-1855.

\section{Appendix}

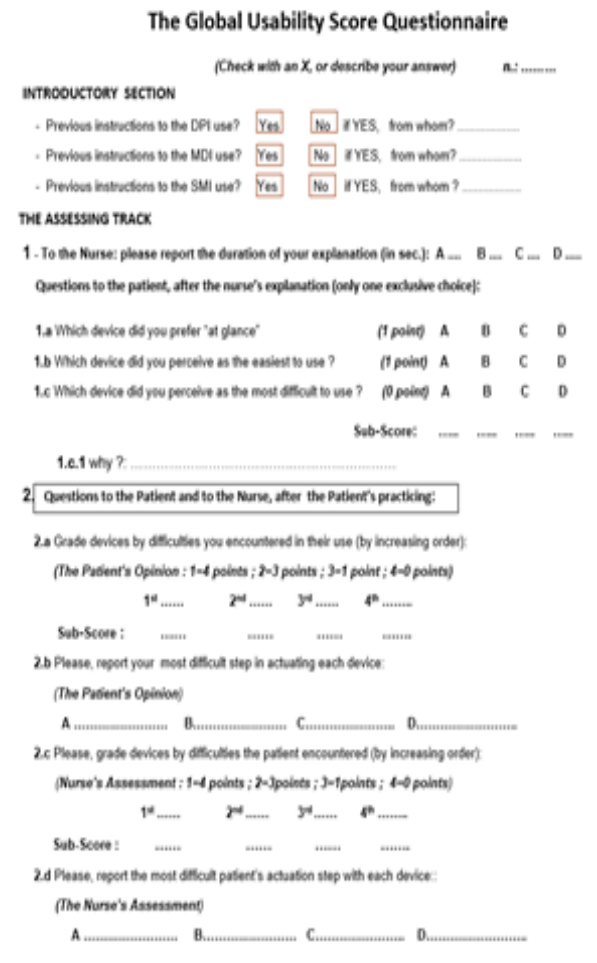

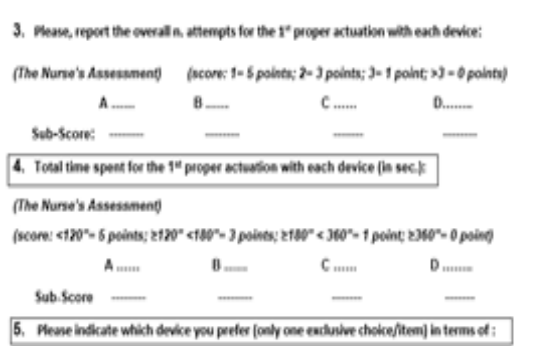

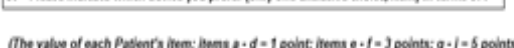

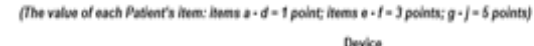

2. Shape
b. Slee

c. Nouthpiect

d. Hyplene

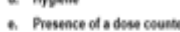

t. Ease ol viping

2. N. eancerwes for actuation

i. Eose of un

\begin{tabular}{|c|c|c|c|c|}
\hline \multirow[b]{2}{*}{ (Apoint) } & \multicolumn{3}{|c|}{ Device } & \\
\hline & A & $B$ & c & 0 \\
\hline (Apoint) & A & $B$ & $c$ & 0 \\
\hline (Apoing) & A & $B$ & $c$ & 0 \\
\hline Apoint & A & B & c & 0 \\
\hline (poohss) & A & B & c & 0 \\
\hline ppoins) & A & B & c & 0 \\
\hline (Spolins) & A & 8 & c & 0 \\
\hline (5poins) & A & $B$ & c & 0 \\
\hline (Spoins) & A & $B$ & c & 0 \\
\hline (Spoints) & A & $B$ & c & 0 \\
\hline sub-scoet & 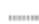 & $=$ & m & $=$ \\
\hline
\end{tabular}

i. Petception of lishaled decese

I. Presence of a tripget value (Spointa)

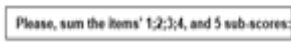

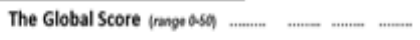

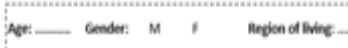

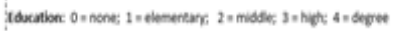
Thank you for your valuablo contribution 


\section{If}

Advances In Industrial Biotechnology | ISSN: 2639-5665

Advances In Microbiology Research | ISSN: 2689-694X

Archives Of Surgery And Surgical Education | ISSN: 2689-3126

Archives Of Urology

Archives Of Zoological Studies | ISSN: 2640-7779

Current Trends Medical And Biological Engineering

International Journal Of Case Reports And Therapeutic Studies | ISSN: 2689-310X

Journal Of Addiction \& Addictive Disorders | ISSN: 2578-7276

Journal Of Agronomy \& Agricultural Science | ISSN: 2689-8292

Journal Of AIDS Clinical Research \& STDs | ISSN: 2572-7370

Journal Of Alcoholism Drug Abuse \& Substance Dependence | ISSN: 2572-9594

Journal Of Allergy Disorders \& Therapy | ISSN: 2470-749X

Journal Of Alternative Complementary \& Integrative Medicine | ISSN: 2470-7562

Journal Of Alzheimers \& Neurodegenerative Diseases | ISSN: 2572-9608

Journal Of Anesthesia \& Clinical Care | ISSN: 2378-8879

Journal Of Angiology \& Vascular Surgery | ISSN: 2572-7397

Journal Of Animal Research \& Veterinary Science | ISSN: 2639-3751

Journal Of Aquaculture \& Fisheries | ISSN: 2576-5523

Journal Of Atmospheric \& Earth Sciences | ISSN: 2689-8780

Journal Of Biotech Research \& Biochemistry

Journal Of Brain \& Neuroscience Research

Journal Of Cancer Biology \& Treatment | ISSN: 2470-7546

Journal Of Cardiology Study \& Research | ISSN: 2640-768X

Journal Of Cell Biology \& Cell Metabolism | ISSN: 2381-1943

Journal Of Clinical Dermatology \& Therapy | ISSN: 2378-8771

Journal Of Clinical Immunology \& Immunotherapy | ISSN: 2378-8844

Journal Of Clinical Studies \& Medical Case Reports | ISSN: 2378-8801

Journal Of Community Medicine \& Public Health Care | ISSN: 2381-1978

Journal Of Cytology \& Tissue Biology | ISSN: 2378-9107

Journal Of Dairy Research \& Technology | ISSN: 2688-9315

тVA

Journal Of Diabetes \& Metabolic Disorders | ISSN: 2381-201X

Journal Of Emergency Medicine Trauma \& Surgical Care | ISSN: 2378-8798

Journal Of Environmental Science Current Research | ISSN: 2643-5020

Journal Of Food Science \& Nutrition | ISSN: 2470-1076

Journal Of Forensic Legal \& Investigative Sciences | ISSN: 2473-733X

Journal Of Gastroenterology \& Hepatology Research | ISSN: 2574-2566
Journal Of Genetics \& Genomic Sciences | ISSN: 2574-2485

Journal Of Gerontology \& Geriatric Medicine | ISSN: 2381-8662

Journal Of Hematology Blood Transfusion \& Disorders | ISSN: 2572-2999

Journal Of Hospice \& Palliative Medical Care

Journal Of Human Endocrinology | ISSN: 2572-9640

Journal Of Infectious \& Non Infectious Diseases | ISSN: 2381-8654

Journal Of Internal Medicine \& Primary Healthcare | ISSN: 2574-2493

Journal Of Light \& Laser Current Trends

Journal Of Medicine Study \& Research | ISSN: 2639-5657

Journal Of Modern Chemical Sciences

Journal of Nanotechnology Nanomedicine \& Nanobiotechnology | ISSN: 2381-2044

Journal Of Neonatology \& Clinical Pediatrics | ISSN: 2378-878X

Journal Of Nephrology \& Renal Therapy | ISSN: 2473-7313

Journal Of Non Invasive Vascular Investigation | ISSN: 2572-7400

Journal Of Nuclear Medicine Radiology \& Radiation Therapy | ISSN: 2572-7419

Journal Of Obesity \& Weight Loss | ISSN: 2473-7372

Journal Of Ophthalmology \& Clinical Research | ISSN: 2378-8887

Journal Of Orthopedic Research \& Physiotherapy | ISSN: 2381-2052

Journal Of Otolaryngology Head \& Neck Surgery | ISSN: 2573-010X

Journal Of Pathology Clinical \& Medical Research

๑ รุ_หษ १: Journal Of Pharmacology Pharmaceutics \& Pharmacovigilance | ISSN

Journal Of Physical Medicine Rehabilitation \& Disabilities | ISSN: 2381-8670

Journal Of Plant Science Current Research | ISSN: 2639-3743

Journal Of Practical \& Professional Nursing | ISSN: 2639-5681

Journal Of Protein Research \& Bioinformatics

Journal Of Psychiatry Depression \& Anxiety | ISSN: 2573-0150

Journal Of Pulmonary Medicine \& Respiratory Research | ISSN: 2573-0177

Journal Of Reproductive Medicine Gynaecology \& Obstetrics | ISSN: 2574-2574

Journal Of Stem Cells Research Development \& Therapy | ISSN: 2381-2060

Journal Of Surgery Current Trends \& Innovations | ISSN: 2578-7284

Journal Of Toxicology Current Research | ISSN: 2639-3735

Journal Of Translational Science And Research

Journal Of Vaccines Research \& Vaccination | ISSN: 2573-0193

Journal Of Virology \& Antivirals

Sports Medicine And Injury Care Journal | ISSN: 2689-8829

Trends In Anatomy \& Physiology | ISSN: 2640-7752

Submit Your Manuscript: https://www.heraldopenaccess.us/submit-manuscript 